DOI 10.37882/2500-3682.2020.10.10

\title{
ОРИГИНАЛЬНЫЙ «ОПРОСНИК ОЦЕНКИ КАЧЕСТВА РЕМИССИИ В УДАЛЕННЫХ И ТРУДНОДОСТУПНЫХ РЕГИОНАХ» (ООКРУТР) КАК СРЕДСТВО ВЫЯВЛЕНИЯ КРИТЕРИЕВ ОЦЕНКИ КАЧЕСТВА ТЕРАПЕВТИЧЕСКОЙ РЕМИССИИ БОЛЬНЫХ АЛКОГОЛИЗМОМ
}

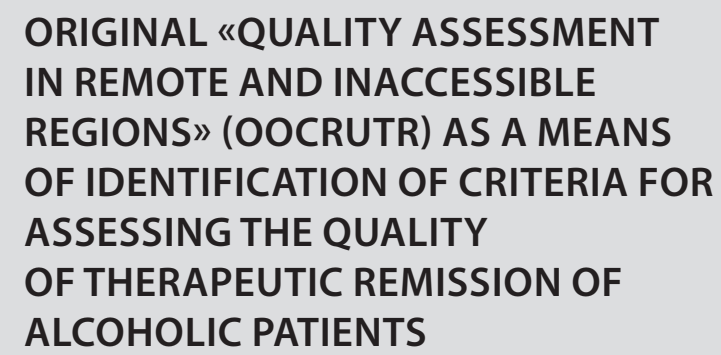

ORIGINAL "QUALITY ASSESSMENT

IN REMOTE AND INACCESSIBLE

REGIONS» (OOCRUTR) AS A MEANS

OF IDENTIFICATION OF CRITERIA FOR

ASSESSING THE QUALITY

OF THERAPEUTIC REMISSION OF

ALCOHOLIC PATIENTS

O. Litvyakova

N. Belopolskaya

Summary: "Questionnaire for assessing the quality of remission in remote and hard-to-reach regions» is designed to work with alcoholic patients living in remote regions of the country with difficult living conditions, social disadvantage. O0KRUTR can be used both for screening and for individual testing - in person and remotely by phone, which not only makes it easier, but in some cases, makes it possible for a psychologist to assess the quality of life in the sobriety of residents of geographically isolated areas with difficult transport and communication systems. The method of structured interviews formed the basis of the "Questionnaire for assessing the quality of remission in remote and hard-to-reach regions» (00KRUTR). The data obtained did not go beyond the reference test data. Based on the results of the work, problem areas were identified with the aim of their possible psychological study in further research.

Keywords: rehabilitation program for alcoholic patients, Chukotka Red Cross, duration of therapeutic remission, questionnaire, assessment of the quality of remission, hard-to-reach and remote regions.
$\mathrm{B}$ отдаленных регионах страны, в частности на Чукотке, алкоголь является самым доступным и эффективным антидепрессантом и адаптогеном к трудным жизненным условиям.

Алкоголизм затрагивает не только сферы жизнедеятельности индивида, но и его ближнего и дальнего окружения, все пласты функционирования личности. От 70 до 90\% людей, страдающих наркотической зависимостью, в том числе, алкоголизмом, находятся в трудоспособном возрасте (Морев, Попова, 2011) [11]. На Чукотке алкоголизм можно сравнить с эпидемией, втягивающей в свою патологическую воронку все возраста (в некоторых алкогольных семьях дети пробуют алкоголь в 6-7 лет), со-
Литвякова Ольга Станиславовна

психолог, педагог-исследователь, Чукотское автономное окружное отделение Российского Красного Креста

(2. Анадырь)

superpolis@gmail.com

Белопольская Наталия Львовна

Д.псх.н., Московский институт психоанализа natalybelopolsky@mail.ru

Аннотация: «Опросник оценки качества ремиссии в удаленных и труднодоступных регионах» предназначен для работы с больными алкоголизмом, проживающими в отдаленных регионах страны с трудными условиями жизни, социальным неблагополучием. 00КРУТР возможно применять, как для скрининга, так и для индивидуального тестирования, - очно и дистанционно по телефону, что не только облегчает, но и в некоторых случаях, делает в0зможной работу психолога по оценке качества жизни в трезвости жителей территориально обособленных районов с трудной транспортной и коммуникационной системами. Метод структурированного интервью составил основу «0просника оценки качества ремиссии в удаленных и труднодоступных регионах» (ООКРУТР). Полученные данные не выходили за референтные данные тестов. По результатам работы были выявлены проблемные зоны с целью их возможной психологической проработки в дальнейших исследованиях.

Ключевые слова: программа реабилитации больных алкоголизмом, Красный Крест Чукотки, продолжительность терапевтической ремиссии, опросник, оценка качества ремиссии, труднодоступные и удаленные регионы. циальные слои общества (от состоятельных людей до совсем бедных), представителей разных национальностей, проживающих на территории Чукотки, как женского населения, так и мужского, (причем женщин, страдающих алкоголизмом никак не меньше). В научной литературе высказываются опасения по поводу влияния алкоголизма на демографическое развитие страны: необратимое разрушение здоровья населения и генофонда в целом в ближайшее время (Малахова, 2012) [10]. Наиболее неблагоприятные прогнозы, на наш взгляд, касаются удаленных и труднодоступных регионов страны в число которых входит обособленная от «материковой» цивилизации (так местные жители называют центральную части России) Чукотка. На Чукотке нет железных дорог, все 
транспортное сообщение осуществляется воздушным (самолеты и вертолеты), водным (в навигацию - теплоход «Капитан Сотников», частные катера, в межсезонье - судна на воздушных подушках) и наземным специальным транспортом (Триколы, вездеходы, снегоходы), а также между некоторыми населенными пунктами, в случае, если проложена дорога - немногочисленным автотранспортом (машины и автобус). Интернет связь плохого качества и дорогостоящая, что составляет большие трудности пользования мессенджерами.

До настоящего времени среди наиболее актуальных проблем в наркологии остается стабильно низкий уровень эффективности лечения химической зависимости: годовые ремиссии не превышают 7 - 15\%, что обусловлено досрочным прерыванием лечения на различных его этапах (Кулаков, Береза, Корчагина, 2014) [9]. Не разработано достоверных критериев оценки эффективности программ лечения и реабилитации в наркологическом стационаре, амбулатории и реабилитационных центрах. Остро стоит вопрос объективизации данных, получаемых при исследовании успешности лечения (Кошкина, Киржанова, Бабичева, Муганцева, 2013; Кошкина, Сиржанова, Гусева, 2015) [7, 8]. Недостаточно исследованы личностные особенности больных хроническим алкоголизмом, проходящих лечение краткосрочными методами психотерапии, именно с этим некоторые авторы связывают неудачи при формировании терапевтической ремиссии (Дунаев, 2006) [4]. Остро стоит вопрос о необходимости повышения уровня оказания лечебно-реабилитационной помощи зависимым от ПАВ (Кулаков, Береза, Корчагина, 2014; Менделевич, 2007) [9, 13] и создания реабилитационного звена (Зыков, 2010; Менделевич, 2007) $[12,13]$. В связи с этим апробация программы реабилитации всей семьи (стационарной и постстационарной частей) и создание опросника ООКРУТР, позволяющего оценить достигнутые результаты лечения можно считать попыткой восполнения недостающих компонентов первичной, вторичной и третичной профилактики алкоголизма.

При разработке программы реабилитации учитывалась специфика региона и выборки: территориальная обособленность, географические, исторические, социокультурные, религиозно-мифологические, нейропсихологические, физиологические особенности (Богораз, 1934; Величковский, 2006; Зуев, 1998, 1999; Менделевич, 2007; Чухрова и соавт., 1999, 2009) $[1,2,5,6,13,15,16]$. Выборка (32 больных) представлена двумя национальностями - чукчи (15 чел.) и русские, рожденные и проживающие на Чукотке на протяжении всей жизни (17 чел.). Выборку можно считать репрезентативной в силу отражения в ней общей тенденции малочисленности жителей в населенных пунктах (от 80 до максимум 1500 чел.), низкой плотности населения, а также соотношения проживающих в поселениях народностей. Численность представителей коренных этносов в большинстве поселений и по всему округу ниже, чем других национальностей, в основном, - русских (в общем по Чукотке - 50\%) и украинцев (6 \%). Коренные народы Чукотки - чукчи, чуванцы, эскимосы, эвены и юкагиры - составляют около $33 \%$ населения ЧАО (по данным Росстата об итогах Bсероссийской переписи населения 2010 г.) [14].

После прохождения краткосрочной программы реабилитации в стационаре рецидив случился сразу у 16 чел. (50 \%), 4 месяца ремиссии было у 16 чел. (50\%), далее - 2 года ремиссии - у 7 чел. (21,9\%), 4 года ремиссии - наблюдалось у 5 чел. (15,63 \%). На протяжении 4-х лет у больных была возможность посещать созданную группу AА, также велось психологическое сопровождение, осуществляемое, в силу их проживания в труднодоступных удаленных поселениях, по телефону и, 1-2 раза в год, очно во время командировок психолога. Также регулярно проводились структурированные и неструктурированные беседы с целью выявить удовлетворенность и качество жизни в трезвости. Эти беседы легли в основу разработанного опросника.

Эффективность программы реабилитации зависимых от алкоголя по методу Я. Маршака мы условились оценивать по двум критериям: во-первых, по продолжительности терапевтической ремиссии на протяжении 4-х месяцев, 1 года, 2-х лет, 3-х лет и 4-х лет после завершения лечения в стационаре, во-вторых, по качеству ремиссии, субъективно оцениваемой респондентами методом опроса и объективно оцениваемой нами в клинической беседе, мотивационном интервью, личных беседах, групповом и индивидуальном общении по телефону и при личных встречах. Качество ремиссии приравнивается нами к качеству жизни. Для оценки качества ремиссии нами был составлен оригинальный «Опросник оценки качества ремиссии в удаленных и труднодоступных регионах» (ООКРУТР) на основе Краткого опросника BO3 (BO3КЖ-100) для оценки качества жизни ( WHOQOLBREF) и «Методов оценки клинического и социального статуса больных АЗ в ремиссии», разработанных в СанктПетербургском научно-исследовательском психоневрологическом институте им. В.М. Бехтерева Л.А. Дубининой и соав. (Дубинина и соавт., 2012) [3].

Целью настоящей работы явилось представление и описание оригинального «Опросника оценки качества ремиссии в удаленных и труднодоступных регионах» (ООКРУТР), а также оценка эффективности данного вида анкетирования для пациентов, не имеющих возможности очного общения со специалистом-психологом.

В рамках настоящего исследования проведён большой научный эксперимент, направленный на выявление основных критериев оценки качества терапевтической ремиссии больных алкоголизмом, который базировал- 
ся на интерпретации ответов пациентов на вопросы оригинального опросника («Опросник оценки качества ремиссии в удаленных и труднодоступных регионах» (ООКРУТР). Помимо анкетирования в методологию исследования входили наблюдение и сравнение.

В качестве ведущих методов теоретического исследования в настоящей работе избраны анализ и синтез.

«Опросник оценки качества ремиссии в удаленных и труднодоступных регионах» (ООКРУТР) предназначен для работы с больными алкоголизмом, проживающими в отдаленных регионах страны с трудными условиями жизни, социальным неблагополучием. ООКРУТР возможно применять, как для скрининга, так и для индивидуального тестирования, - очно и дистанционно по телефону, что не только облегчает, но и в некоторых случаях, делает возможной работу психолога по оценке качества жизни в трезвости жителей территориально обособленных районов с трудной транспортной и коммуникационной системами. Опросник применим для оценки качества как терапевтической, так и других видов ремиссии (спонтанной, мотивационной и др.)

Опросник предназначен для самостоятельного заполнения, вопросы, указанные в нем, измеряют индивидуальное восприятие пациентом вопросов, характеризующих качество ремиссии.

Общее значение качества жизни и все значения по каждому вопросу в разработанном оригинальном опроснике шкалируются в двух направлениях: позитивном направлении - более высокие значения соответствуют более высокому качеству жизни в трезвости и в негативном направлении - более высокие значения показывают низкое качество ремиссии. Вопросы позитивно и негативно ориентированы.

Из опросника были исключены вопросы о физическом самочувствии, медицинской помощи, концентрации внимания, удовлетворенности своим внешним видом, о доступности информации, транспортной доступности («Насколько легко Вы можете добраться до нужных Вам мест?») и удовлетворенности используемым транспортом, своею трудоспособностью, условиями в месте проживания, доступностью медицинского обслуживания. Вопрос об удовлетворенности своим сном заменён вопросом относительно частоты алкогольных сновидений, которые ряд авторов (Юрченко, 1999) [17] рассматривают как маркер актуализации ПВА. Появление сновидений с алкогольной тематикой даже при внешне устойчивой ремиссии может свидетельствовать об актуализации влечения к алкоголю (В. Н. Касаткин, 1967, В.Б. Альтшулер, 1984, 1994; И.В. Бокий, С.В. Цыцарев, 1967; А.Г. Гофман, И.В. Александрова, 1991; И.В. Чередниченко, В.Б. Альтшулер, 1992; Г.В. Заневич, С.С. Ли- бих, 1965, Л.Н. Юрченко) (Юрченко, 1999) [17], в связи с чем важен анализ даже единичных сновидений, а также факторов и состояний, спровоцировавших их. Важность анализа алкогольных сновидений основывается на описанном 3. Фрейдом механизме исполнения желаний во сне (Юрченко, 1999) [17].

Оставшиеся вопросы были дополнены и адаптированы для понимания больными алкоголизмом с учетом разного уровня образования и интеллекта, возможности восприятия на слух при дистанционном опросе по телефону, был включен блок вопросов, предполагающих качественную описательную оценку ремиссии и своих состояний.

Инструкция: Опросник нацелен выявить Вашу точку зрения на качество Вашей жизни. Я буду зачитывать вслух вопрос и называть вариант ответа на него, ваша задача выбрать наиболее подходящий вам ответ. В случае возникновения каких-либо сомнений при выборе ответа, выбирайте тот ответ, который первым приходит в голову. Я хочу обратить ваше внимание на то, что ответы на вопросы должны учитывать ваши взгляды на жизнь, надежды, принципы, увлечения и интересы. Какой Вы считаете свою жизнь в течение последних четырех недель?

\section{Результаты и их анализ}

Обработка и интерпретация результатов теста

Подсчитывается суммарный балл.

Ответам испытуемого на прямые вопросы:

$1,2,3,4,5,6,7,8,9,10,12,13,16,17,19,20,24,26$, приписываются баллы в прямой последовательности:

Таблица 2

Ключ к опроснику

\begin{tabular}{|l|l|l|l|l|}
\hline Вариант ответов & 1 & 2 & 3 & 4 \\
\hline Баллы & 1 & 2 & 3 & 4 \\
\hline
\end{tabular}

Ответам испытуемого на обратные вопросы:

$11,14,15,18,21,22,23,25$, приписываются баллы в обратной последовательности:

Таблица 3

Ключ к опроснику

\begin{tabular}{|l|l|l|l|l|}
\hline Вариант ответов & 1 & 2 & 3 & 4 \\
\hline Баллы & 4 & 3 & 2 & 1 \\
\hline
\end{tabular}

В результате подсчетов суммарных баллов низкие показатели качества ремиссии соответствуют диапазону от 26 до 51 балла, средние - от 52 до 78 баллов, высокие показатели качества ремиссии - от 79 до 104 баллов.

26-51 балла - ремиссия считается низкого качества, 
Таблица 1

Опросник оценки качества ремиссии в удаленных и труднодоступных регионах

\begin{tabular}{|c|c|c|c|c|c|}
\hline & \multirow[t]{2}{*}{ Вопросы } & \multicolumn{4}{|c|}{ Варианты ответов } \\
\hline & & 1 & 2 & 3 & 4 \\
\hline 1. & Довольны ли вы своей жизнью в настоящий момент? & нет & не очень & да & очень \\
\hline 2. & Какое настроение у вас в данный момент? & плохое & по-разному & хорошее & отличное \\
\hline 3. & Какое настроение бывает у вас чаще всего? & плохое & по-разному & хорошее & отличное \\
\hline 4. & Насколько безопасно Вы себя ощущаете в повседневной жизни? & нет & не очень & да & очень \\
\hline 5. & $\begin{array}{l}\text { Хватает ли Вам сил для повседневной жизни или выполнения повседневных } \\
\text { обязанностей? }\end{array}$ & нет & не очень & да & очень \\
\hline 6. & Насколько Вы хорошо себя чувствуете? & плохо & по-разному & хорошо & отлично \\
\hline 7. & Насколько комфортно вы себя чувствуете в семье, с родственниками? & плохо & по-разному & хорошо & отлично \\
\hline 8. & С каким настроением Вы идете на работу? & плохое & по-разному & хорошее & отличное \\
\hline 9. & С каким настроением Вы возвращаетесь с работы домой? & плохое & по-разному & хорошее & отличное \\
\hline 10. & Чувствуете ли вы в себе энергию для повседневной жизни и работы? & никогда & иногда & часто & очень часто \\
\hline 11. & Как часто Вы чувствуете, что измотаны и у Вас совершенно нет сил? & никогда & иногда & часто & очень часто \\
\hline 12. & Хватает ли вам денег на свои расходы? & нет & не очень & да & очень \\
\hline 13. & Вы часто можете себе позволить отдых и развлечения? & никогда & иногда & часто & очень часто \\
\hline 14. & Как часто Вы чувствуете себя голодным? & никогда & иногда & часто & очень часто \\
\hline 15. & Как часто Вам снится, что Вы употребляете алкоголь? & никогда & иногда & часто & очень часто \\
\hline 16. & Насколько Вы довольны собой? & нет & не очень & да & очень \\
\hline 17. & Вы удовлетворены личными взаимоотношениями? & нет & не очень & да & очень \\
\hline 18. & Как часто Вы злитесь? & никогда & иногда & часто & очень часто \\
\hline 19. & Вы удовлетворены свое сексуальной жизнью? & нет & не очень & да & очень \\
\hline 20. & Вы получаете поддержку от своих друзей? & никогда & иногда & часто & очень часто \\
\hline 21. & У Вас часто бывают плохое настроение, тревога, депрессия? & никогда & иногда & часто & очень часто \\
\hline 22. & Как часто у Вас возникает желание употребить алкоголь? & никогда & иногда & часто & очень часто \\
\hline 23. & Как часто Вы чувствуете себя уставшим? & никогда & иногда & часто & очень часто \\
\hline 24. & $\begin{array}{l}\text { Вы применяете навыки, полученные в программе реабилитации для пре- } \\
\text { одоления плохого настроения, тревоги, депрессия, одиночества? }\end{array}$ & никогда & иногда & часто & очень часто \\
\hline 25. & Как часто Вы чувствуете себя одиноким? & никогда & иногда & часто & очень часто \\
\hline \multirow[t]{2}{*}{26.} & Вы пытаетесь реализовать Ваши мечты и цели? & никогда & иногда & часто & очень часто \\
\hline & \multicolumn{5}{|c|}{ Вопросы для качественной оценки: } \\
\hline 27. & 0 чем вы мечтаете в ближайшее время и в перспективе? & & & & \\
\hline 28. & В чем главная цель вашей жизни? & & & & \\
\hline 29. & $\begin{array}{l}\text { Что из программы реабилитации было для вас наиболее (самым) значи- } \\
\text { мым/ценным }\end{array}$ & & & & \\
\hline 30. & Что из программы реабилитации помогает сегодня Вам оставаться трезвым & & & & \\
\hline 31. & Назовите свое самое большое достижение за последний год & & & & \\
\hline
\end{tabular}


с присутствием тревожных и депресивных проявлений, сниженного настроения, отсутствия сил и энергии для выполнения повседневных дел, ощущением одиночества и неудовлетворенностью собой и своей жизнью взаимоотношениями с родственниками, высокой конфликтностью в семье, отсутствием истинных желаний и целей и субъективно оцениваемой возможности для их реализации, инфляцией мечты, отсутствием адаптивных копинг-стратегий для преодоления трудных жизненных и эмоциональных ситуаций, нежеланием что-либо делать для решения возникающих проблем, в том числе следовать навыкам, полученных в программе реабилитации, неверием в свои силы и возможности, часто возникающее патологическое влечения к алкоголю (ПВА), высокий риск развития срыва и рецидива.

52-78 баллов - ремиссия среднего качества с периодическими тревожными и депрессивными состояниями, иногда возникающим ощущением одиночества, ситуативным снижением настроения, сформированными навыками адаптивных копинг-стратегий, которые применяются на практике не всегда, в зависимости от ситуации и настроения, средняя степень конфликтности, удовлетворенности собой и своими возможностями по реализации своих жизненных планов, способность планировать, но не всегда достигать намеченных целей, средний уровень жизненной энергии, сил и энергии для выполнения повседневных дел, периодически возникающее ПВА, имеется потенциал из навыков, приобретенных при реабилитации или лечении для его преодоления, средний уровень вероятности развития срыва и рецидива.

79-104 балла - ремиссия высокого качества с преобладанием хорошего настроения, минимальным количеством тревожных и депрессивных состояний, возможных ситуативно и не доминирующих в эмоциональном фоне, верой в себя и свои силы, сформированными конструктивными копинг-стратегиями, позволяющими обращаться за помощью в решении сложных жизненных ситуаций и преодолении возможных депрессивных со- стояний к значимым другим, удовлетворенностью жизнью, взаимоотношениями в семье и на работе, редко или очень редко возникающее ПВА, низкий риск развития срыва и рецидива.

Однако, интервал 98-104 балла может свидетельствовать о вытеснении проблем, беззаботном, безответственном отношении к своей жизни на определенном ее этапе, возможно, связанном со значимым эмоционально-положительным событием (влюбленность, свадьба, повышение по работе, новоселье и т.д.). Поэтому при получении столь высоких баллов желательно уточнять их причину.

Таким образом, переработанный в плане содержания и структуры оригинальный «Опросник оценки качества ремиссии в удаленных и труднодоступных регионах» (ООКРУТР) обнаруживает свою эффективность при анализе уровня ремиссии у больных алкоголизмом. Вид опросника значительно расширяет возможность психолога по работе с данной группой пациентов, поскольку позволяет проводить тест дистанционно (с применением средств информационно-коммуникационных технологий).

Вопросы для качественной оценки не имеют количественного выражения и предназначены для выявления проблемных зон с целью их возможной психологической проработки в дальнейшем.

Однако следует заметить, что в рамках настоящего исследования тест опробован на малочисленной выборке (16 человек, 5 семей), в которой его результаты соответствуют объективным характеристикам качества ремиссии, полученным методами наблюдения, беседы, опроса микроокружения респондентов, страдающих алкоголизмом и их семей. Опросник требует дополнительной валидизации на большей репрезентативной выборке, что определяет необходимость дальнейшей разработки заявленной темы, намечает пути новых научных изысканий по данной проблеме.

ЛИТЕРАТУРА

1. Богораз В.Г. Чукчи / Авторизованный перевод с английского / Часть І. Научно-исследовательская ассоциация Института народов севера ЦИК сссР. Материалы по этнографии. Ленинград: Издательство Института народов Севера ЦИК СССР, 1934. V т.

2. Величковский Б.Т. Полярная одышка [Электронный ресурс] // Социальное партнерство. 2006. № 3. Режим доступа: http://www.oilru.com/.

3. Дубинина Л.А. Клинические и социально-психологические критерии оценки реадаптации больных алкогольной зависимостью на этапах становления ремиссии Методические рекомендации. Пособие для врачей / СПб НИПНИ им. В.М. Бехтерева, 2012.

4. Дунаев А.Г. Индивидуально-психологические особенности личности больных хроническим алкоголизмом с различной длительностью психотерапевтической ремиссии: дис. ... канд. психол. наук: 19.00.01 / Ростов-на-Дону, 2006. 151 с., с. 35

5. Зуев А.С. Характер присоединения Сибири в новейшей отечественной историографии. / Евразия: культурное наследие древних цивилизаций. Вып.1. Культурный космос Евразии. Новосибирск, 1999. С. 124-136.

6. Зуев А.С. Хроника присоединения крайнего Северо-Востока Сибири к России в XVII - первой четверти XVIII вв. [Электронный ресурс] // Сибирская Заимка. 1998. Режим доступа: http://zaimka.ru/zuev-chukchi/ 
7. Кошкина Е.А., Киржанова В.В., Бабичева Л.П., Муганцева Л.А. Деятельность наркологической службы Российской Федерации: оценка статистических показателей и анализ результатов // Журнал неврологии и психиатрии им. С.С. Корсакова 2013; 2 (6):3-8.

8. Кошкина Е.А., Сиржанова В.В., Гусева 0.И. Мониторинг и оценка эффективности наркологической службы в условиях ее модернизации: проблемы и пути их решения [Электронный ресурс] / Эл №ФС77-28654. Социальные аспекты здоровья населения. 2015. Режим доступа: http://vestnik.mednet.ru

9. Кулаков С.А., Береза Ж.В., Корчагина Е.К. Комплексная медицинская (психотерапевтическая) модель реабилитации пациентов с химическими и нехимическими формами аддикций, расстройствами личности, а также членов их семей // Психическое здоровье. 2014. № 1. С. 16-22.

10. Малахова Ж.Л. Клинико-патогенетические основы фетального алкогольного синдрома у детей раннего возраста: автореф. дис. ... д-ра мед. наук: 14.01.08 / Екатеринбург, 2012.62 с.

11. Морев М.В., Попова В.И. Социальный портрет страдающих алкоголизмом и наркоманией // Проблемы развития территории. 2011. Вып. 1 (53). С. 67-76.

12. Профилактика патологических форм зависимого поведения: в 3 т. / Лечебная субкультура: технологии профилактики рецидива (третичная профилактика). М: РБФ НАН, 2010. 312 с. 3 т.

13. Руководство по аддиктологии / Под ред. проф. В.Д. Менделевича. СПб.: Речь, 2007.768 с.

14. Численность населения наиболее многочисленных национальностей по субъектам Российской Федерации // Сводные итоги Всероссийской переписи населения 2010 года. Федеральная служба государственной статистики. 2010. Том 11. Режим доступа: http://www.gks.ru/free_doc/new_site/perepis2010/ croc/perepis_itogi1612.htm (Дата обращения: 17.12.2018).

15. Чухрова М.Г. Основные направления профилактики алкоголизма среди коренного населения с учетом культуральных и психологических особенностей // Мир науки, культуры, образования. 2009. № 7 (19) 2. С. $225-228$.

16. Чухрова М.Г., Курилович С.А., Леутин В.П. Патофизиологические и психосоматические аспекты потребления алкоголя в Туве / Новосибирск: Изд-во СО PAMH, 1999. $148 \mathrm{C}$.

17. Юрченко Л.Н. Клинико-катамнестическое исследование эффективности психотерапии алкоголизма: автореф. дисс. ... канд. мед. наук: $14.00 .45,14.00 .18$ / Рязань, 1999. 23 с.

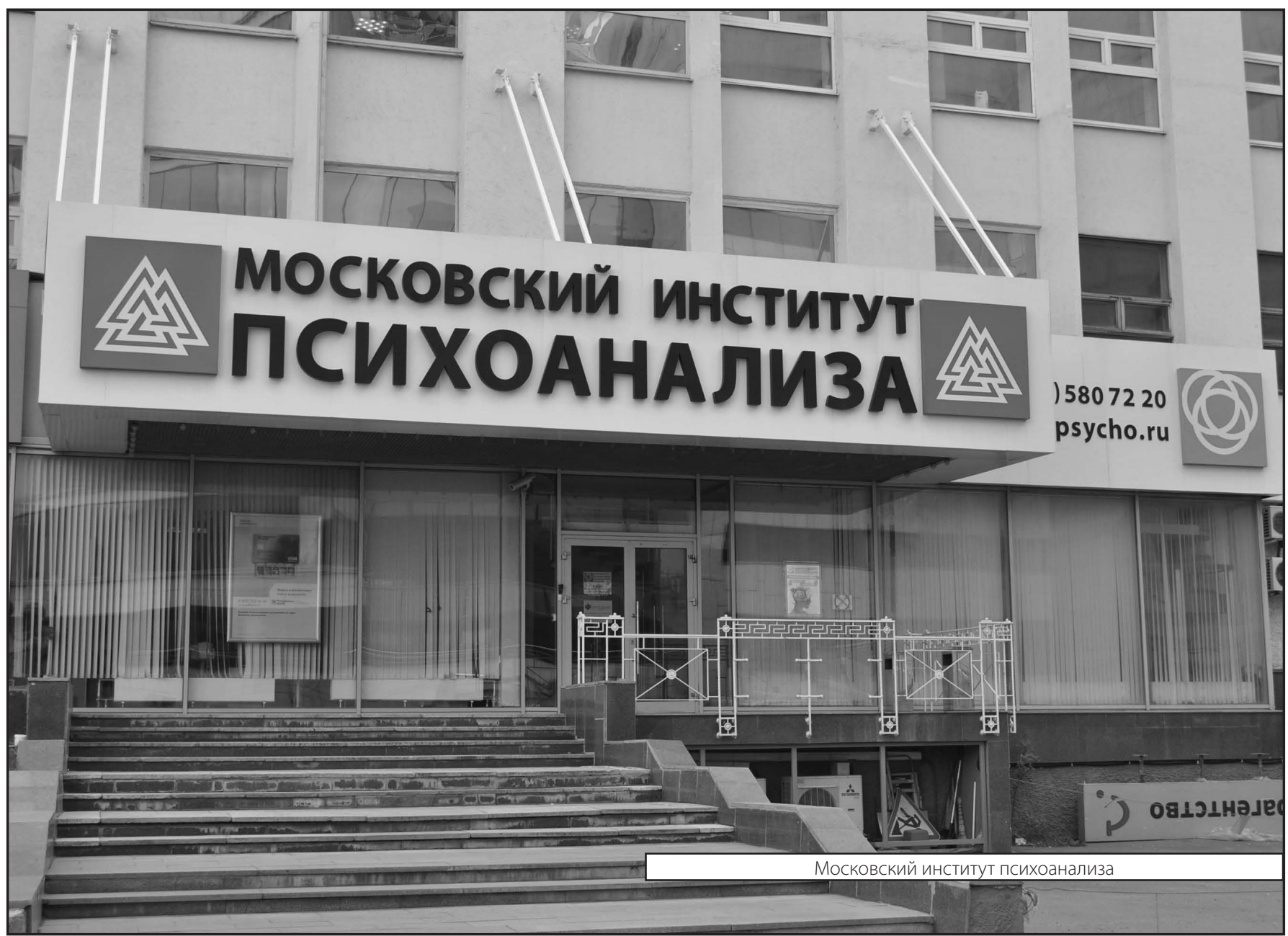

